\title{
Metabolic syndrome: Waist not want not
}

Background and epidemiology:

The metabolic syndrome refers to a constellation of clinical factors associated with an increased risk of diabetes and coronary artery disease. These factors include abdominal obesity, hypertension, dyslipidemia, impaired glucose metabolism, prothrombotic state and proinflammatory state. Also called the dysmetabolic syndrome, syndrome $\mathrm{X}$ or insulin resistance syndrome, this condition entered the scientific lexicon about 15 years ago as investigators sought to understand the link between insulin resistance and other metabolic factors in the development of coronary $\widetilde{\sim}$ artery disease. Consistent, comprehensive results accumulated since then have not only confirmed that this syndrome leads of to heart disease, but they have also demonstrated that modest interventions, such as changes $\varnothing$ in diet and physical activity

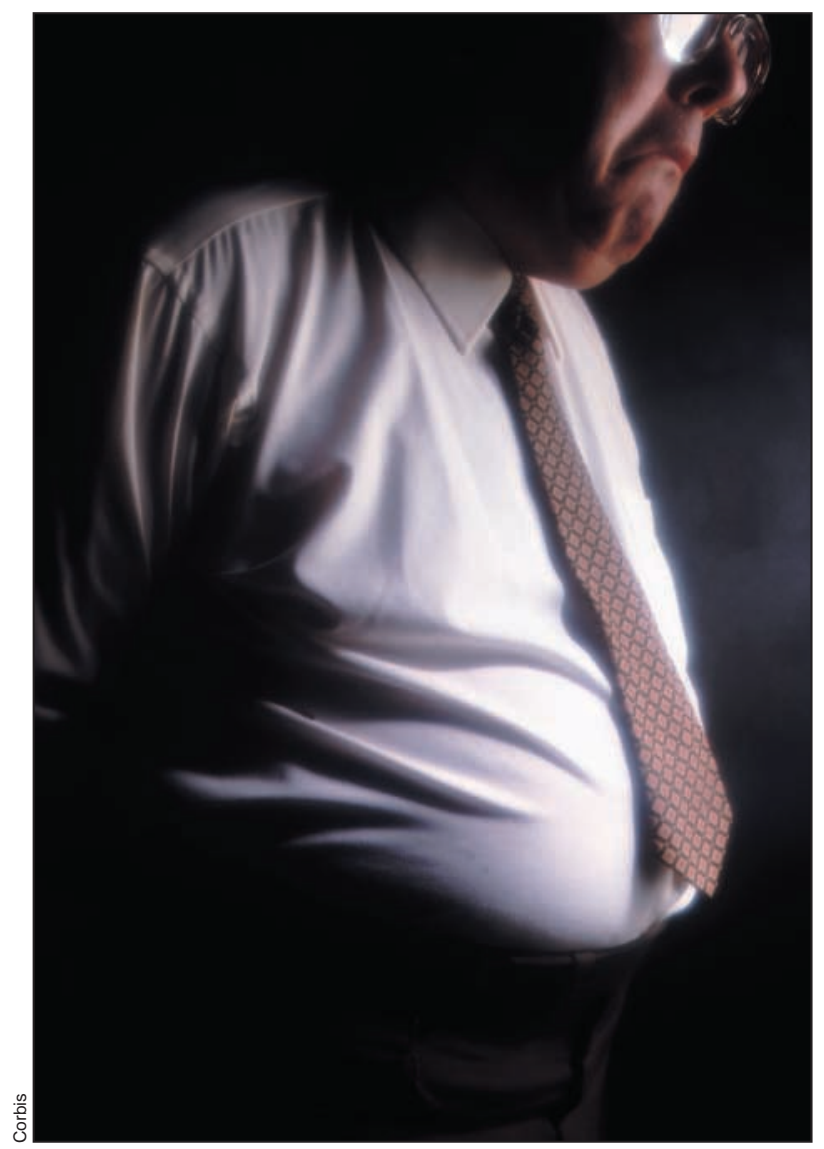

level, may effectively control this syndrome and prevent outcomes such as diabetes.

Recently efforts have focused on translating this knowledge into changes in clinical practice, allowing both clinicians and researchers to define and manage this syndrome better. In 2001 the American National Cholesterol Education Program (NCEP) issued its Adult Treatment Panel III (ATP III) guidelines outlining criteria for the diagnosis of metabolic syndrome. ${ }^{1}$ In the same year, the US Centers for Disease Control and Prevention, at the request of the American Association of Clinical Endocrinologists, introduced a new ICD-9-CM code (277.7) and a set of clinical descriptors of dysmetabolic syndrome $X$.

The rising prevalence of this syndrome in industrialized nations has largely been attributed to lifestyle changes in diet and physical activity, leading to higher obesity rates. In 2002 analysis of data from the Third National Health and Nutrition Examination Survey collected between 1988 and 1994 indicated that a whopping $44 \%$ of the American population aged 50 years and older had the metabolic syndrome, according to NCEP definitions. ${ }^{2}$ The prevalence increased with age, elevated body weight and membership in certain ethnic populations such as Hispanics and Native Americans. Additional research indicated that the syndrome was associated with a tripling of cardiovascular disease mortality and a doubling of overall mortality in a cohort of middle-aged Finnish men. ${ }^{3}$ Given that more than $40 \%$ of adults over age 50 are estimated to have this syndrome, ${ }^{2}$ these results have tremendous implications for future disease burden related to diabetes and coronary artery disease.
Clinical practice: According to ATP III criteria, metabolic syndrome is present in people with 3 or more of the risk factors (see list at left). For patients aged 35 and older in whom the syndrome is suspected, primary care physicians can easily measure the blood pressure, fasting glucose level, and high- and low-density lipoprotein cholesterol levels. To measure waist circumference, they need to place a tape measure at the level of the superior iliac crest, parallel to the floor, at the end of a patient's relaxed expiration.

Managing metabolic syndrome involves both lifestyle modification and, if required, drug therapy. First-line therapies for all risk factors associated with the syndrome are dietary changes and increased physical activity aimed at weight reduction. This means eating small, regular, balanced meals following Health Canada's food guide (www.hc-sc.gc.ca/hpfbdgpsa/onpp-bppn/food_guide_ rainbow_e.html) and participating in daily regular exercise along the lines of Health Canada's physical activity guide (www .hc-sc.gc.ca/hppb/paguide). Additional therapeutic interventions include treatment of hypertension, use of ASA in patients with coronary artery disease to reduce the prothrombotic state and treatment of elevated triglyceride and low HDL cholesterol levels, if required.

Prevention: The slippery slope of the metabolic syndrome toward diabetes and coronary artery disease is not necessarily irreversible. Results from the Diabetes Prevention Research Group $^{5}$ suggest that relatively modest weight loss $(5 \%-7 \%)$ and modest increases in physical activity (150 minutes/week) can reduce the risk of diabetes in obese people with early glycemic impairment (absolute risk reduction over 3 years 
$14.5 \%$, number-needed-totreat 6.9). However, combatting the inertia of sedentary and indulgent habits may be more difficult than preventing these habits in the first place. Global efforts, extending from schoolyard grounds to the heights of the World Health Organization, are currently committed to promoting healthy diets and activity levels and preventing obesity and deconditioning through stakeholder involvement, public and private collaboration, advocacy, evidence and play (www.who .int/hpr/global.strategy.shtml).

\section{Erica Weir}

Associate Medical Officer of Health

Kingston, Frontenac and Lennox \&

Addington Health Unit

Kingston, Ont.

Lorraine Lipscombe

Division of Endocrinology and

Metabolism

Sunnybrook and Women's College

Health Sciences Centre

Toronto, Ont.

\section{References}

1. Expert Panel on Detection, Evaluation, and Treatment of High Blood Cholesterol in Adults. Executive summary of the third report of the $\mathrm{Na}-$ tional Cholesterol Education Program (NCEP) Expert Panel on Detection, Evaluation, and Treatment of High Blood Cholesterol in
Adults (Adult Treatment Panel III). 7AMA 2001;285(19):2486-96.

2. Alexander CM, Landsman PB, Teutsch SM, Haffner SM. NCEP-defined metabolic syndrome, diabetes, and prevalence of coronary heart disease among NHANES III participants age 50 years and older. Diabetes 2003;52:1210-14.

3. Lakka HM, Laaksonen DE, Lakka TA, Niskanen LK, Kumpusalo E, Tuomilehto J, et al. The metabolic syndrome and total and cardiovascular disease mortality in middle-aged men. 7AMA 2002;288(21):2709-16.

4. Hill J. What to do about the metabolic syndrome? Arch Intern Med 2003:163:395-7.

5. Knowler WC, Barrett-Connor E, Fowler SE, Hamman RF, Lachin JM, Walker EA, et al; Diabetes Prevention Program Research Group. Reduction in the incidence of type 2 diabetes with lifestyle intervention or metformin. N Engl 7 Med 2002;346: 393-403.

\section{SERVICE DE RECOMMANDATION BANCAIRE MD}

\section{COMPTEZ SUR NOUS POUR VOTRE HYPOTHËUE.}

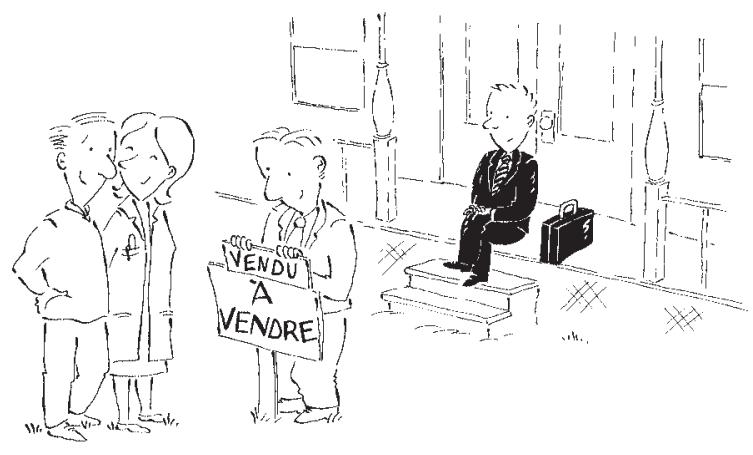

Et emménagez plus vite.

Accédez facilement à votre propriété. Appelez votre planificateur financier de MD pour connaître nos solutions hypothécaires.

$1866792-1112$ •srb.md.amc.ca

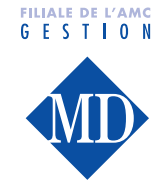

Conçus pour les médecins. Axés sur vos besoins. 